\title{
Por que os conselhos não funcionam? Entraves federativos para a participação popular no Brasil
}

Nilo Lima de Azevedo

Universidade Estadual do Norte Fluminense, Campos dos Goytacazes, RJ, Brasil

Mauro Macedo Campos

Universidade Estadual do Norte Fluminense, Campos dos Goytacazes, RJ, Brasil

Rodrigo Anido Lira

Universidade Candido Mendes, Rio de Janeiro, RJ, Brasil

Este artigo busca contribuir para o debate sobre a efetividade dos conselhos municipais e as dificuldades para o seu funcionamento no Brasil, trazendo à luz variáveis e argumentos pouco explorados em trabalhos similares, como o federalismo, a coordenação de políticas públicas e accountability. A argumentação central utilizada se encontra no trabalho de Guillermo O'Donnell. Segundo o autor, a fragilidade das novas democracias estaria na accountability horizontal, que trata do arranjo institucional de responsabilização por meio de agências governamentais.

Palavras-chave: federalismo, conselhos municipais, efetividade, controle social, ação coletiva
Why Don't Councils Work? Federative Barriers to Popular Participation in Brazil contributes to the debate about the effectiveness of municipal councils and the difficulties for their functioning in Brazil, introducing further explanatory variables and arguments, poorly explored in similar works, such as federalism, coordination of public policies and accountability. The central argument is found in Guillermo O'Donnell's work. According to the author, the fragility of new democracies lies in the horizontal accountability, which deals with institutional arrangement through governmental agencies of accountability.

Keywords: federalism, municipal councils, effectiveness, social control, collective action

\section{Introdução}

Foi a audácia inovadora, a arquitetura da Constituinte, recusando anteprojeto forâneo ou de elaboração interna. O enorme esforço admissionado pelas 61 mil e 20 emendas, além de 122 emendas populares, algumas com mais de 1 milhão de assinaturas, que foram apresentadas, publicadas, distribuídas, relatadas e votadas no longo caminho das subcomissões até a redação final. (...) Há, portanto, representativo e oxigenado sopro de gente, de rua, de praça, de favela, de fábrica, de trabalhadores, de cozinheiras, de menores carentes, de índios, de posseiros, de empresários, de estudantes, de aposentados, de servidores civis e militares, atestando a contemporaneidade e autenticidade social do texto que ora passa a vigorar (CÂMARA DOS DEPUTADOS, 2006).

A citação acima integra o discurso do então deputado federal Ulysses Guimarães, presidente da Assembleia Nacional Constituinte, quando promulgava, em 5 de outubro de 1988, a Constituição da República Federativa do Brasil (BRASIL, 1988), o principal produto político legal da redemocratização brasileira ocorrida em meados dos anos 1980. Esse trecho é particularmente significativo para o que se pretende neste artigo, pois demonstra a importância do espaço da participação social na formação do ideário político democrático já na 
elaboração do texto constitucional e, posteriormente, em vários dispositivos constitucionais e infraconstitucionais que tratam da gestão participativa das políticas públicas.

As evidências de uma ação mais participativa podem ser percebidas, claramente, em relação ao processo de implementação do Sistema Único de Saúde (SUS). A construção de um sistema único e universal foi "resultado de uma intensa mobilização social, que teve início em São Paulo, em meados de 70, ganhando visibilidade nacional no início dos anos 90" (TATAGIBA, 2002, p. 51). A formatação legal do SUS, expressa na Constituição Federal de 1988, originou de uma emenda popular apresentada na Constituinte de 1986, que estabelece a descentralização e a participação social entre as diretrizes desse sistema. Foram definidos também os critérios de financiamento por fundo próprio, com atribuições de acompanhamento e fiscalização por conselhos descentralizados de saúde. Em outras palavras, o que impulsionou a participação foi exatamente uma iniciativa popular, respaldada pela legislação constitucional, o que fortaleceu seu posicionamento frente a quaisquer contestações legais sobre o que viria a ser o formato participativo institucional brasileiro.

Desse modo, o modelo estabelecido pelo SUS é um exemplo fecundo para o que se pretende como proposta de discussão para este artigo. Afinal, é um sistema no sentido mais amplo da palavra, pois leva em conta a relação entre todos os entes federativos (a União, os estados membros, o Distrito Federal e os municípios) na política de provisão de um serviço público. O desenho institucional federativo do SUS inaugurou uma maneira de se pensar e coordenar as políticas públicas de âmbito nacional, segundo o modelo federalista vigente no país, sendo replicado em suas diretrizes gerais para outras políticas públicas, como a assistência social e educação.

Esse sistema gerou amplos debates sobre a sua efetividade pela via da descentralização, como sinônimo de participação e democracia, o que com o decorrer do tempo não se mostrou verossímil. O conjunto do trabalho de autores como Marta Arretche (1996, 2000, 2004), Fernando Abrucio $(1998,2005)$ e José Ângelo Machado (2007), dentre tantos outros, decifrou a relação entre centralização e descentralização do Estado brasileiro após 1988. Os desdobramentos referentes aos efeitos do processo de descentralização no Brasil colocaram na agenda de pesquisa a importância do federalismo para a compreensão da relação entre centralização e descentralização do Estado e das capacidades estatais para a condução de políticas públicas a serem implementais pelos governos subnacionais.

Os sistemas nacionais de coordenação federativa de políticas públicas instaurados no Brasil, os quais incluem a política de saúde, de seguridade social e de educação, estão regulamentados por uma rede normativa complexa que demanda condições efetivas de coordenar esse conjunto de entes federados autônomos. Necessitam, assim, de uma interpretação sistemática para a percepção do funcionamento de seus elementos e de suas instituições, compostos por órgãos 
gestores, conselhos, planos, programas, sistemas de financiamento e de fundos, audiências, conferências, formas de monitoramento e de controle, relações federativas, entre outros. É a partir desse emaranhado de instituições, normas e instrumentos que acreditamos ser possível oferecer uma contribuição original para o debate sobre a efetividade dos conselhos municipais no Brasil.

\section{Pensando os obstáculos ao funcionamento efetivo dos conselhos municipais}

O problema da efetividade é frequentemente levantado na literatura que se dedica ao estudo dos conselhos municipais como instrumentos de participação social e controle das políticas públicas. Neste artigo, buscamos sistematizar os principais obstáculos que tais estudos apresentam para o funcionamento efetivo dos conselhos municipais.

Iniciado em 2001, um levantamento importante sobre as dificuldades de operacionalização dos conselhos foi realizado pelo Observatório das Metrópoles, vinculado ao Instituto de Pesquisa e Planejamento Urbano e Regional (IPPUR) da Universidade Federal do Rio de Janeiro (UFRJ). O estudo almejou definir o perfil dos conselheiros nas regiões metropolitanas do Rio de Janeiro, Belo Horizonte, São Paulo, Recife e Belém. O questionário da pesquisa incluía a seguinte questão relativa aos obstáculos percebidos pelos conselheiros: "Na sua opinião, quais as principais dificuldades no funcionamento do conselho do qual o sr(a). participa?" (AZEVEDO, SANTOS JR. e RIBEIRO, 2004). As opções de resposta eram: Falta de capacitação dos membros do conselho; Não cumprimento das decisões pelo Poder Executivo; Falta de representatividade; Falta de informação; Ausência de diálogo com o representante do Poder Executivo; Ausência de diálogo e negociação com representantes do Poder Executivo; Nenhum; e Outros (Idem).

As principais fragilidades levantadas pela pesquisa, há mais de uma década, em relação à efetividade dos conselhos foram a dificuldade em acessar informação, a falta de capacidade fiscalizatória e uma débil prestação de contas por parte do prefeito ou secretário aos conselheiros. Apontou-se também uma preocupação atinente à questão federativa, conhecida como prefeituralização, em que se percebeu que os conselhos em vários municípios eram meramente criados para cumprir uma determinação burocrática e homologar o repasse de recursos fundo a fundo do Governo Federal, ou verbas estaduais, chamadas de "dinheiro carimbado" para determinada política (Ibid., p. 51). Até hoje, tais fragilidades fazem parte do cotidiano dos conselhos e do ideário sobre instituições criadas na Constituição de 1988, representando uma janela aberta para a dificuldade da participação social. Esse cenário se torna ainda mais complexo quando se acrescenta a capacidade de coordenação federativa das políticas públicas nos seus incentivos e entraves. 
Em relação a isso, o Instituto de Pesquisa Econômica Aplicada (Ipea), em parceria como o Projeto Democracia Participativa da Universidade Federal de Minas Gerais (UFMG), promoveu uma oficina sobre efetividade das instituições participativas em 2010. O evento contou com a participação de pesquisadores reconhecidos no estudo das instituições participativas, cuja efetividade eles buscaram compreender e avaliar. O resultado desse tour de force foi a publicação do livro Efetividade das instituições participativas no Brasil: Estratégias de avaliação (PIRES, 2011), uma referência essencial no campo.

Remetendo à ideia de efetividade da deliberação, busca-se compreender os meios pelos quais ocorre a interação entre governo e sociedade. Em outras palavras, qual a racionalidade que sustenta e promove os acordos e os consensos possíveis entre atores assimétricos em interesses e poder.

A efetividade deliberativa pode ser vista como um momento deliberativo, que possibilita

(...) concentrar para pensar a sua efetividade em diferentes momentos ou aspectos contextuais da
participação. Isso quer dizer, por outro lado, que o elemento deliberativo constitui apenas um momento
e é necessário agregar outros elementos avaliativos neste debate capaz de gerar indicadores ou
resultados mais gerais em relação aos processos deliberativos (AVRITZER, 2011, p. 16).

A ampliação do escopo avaliativo aproxima o debate centrado na efetividade da deliberação à efetividade das instituições participativas, relacionadas como campo das políticas públicas no que refere à qualidade do provimento destas e à capacidade das instituições em influenciar e compartilhar o processo e as decisões políticas realizadas pelo governo.

Roberto Pires et al. (2011) sintetiza os temas relacionados às instituições participativas em cinco dimensões: inclusão e representatividade; desenho institucional; deliberação; contextos e ambiente institucional; e atores e estratégias.

De fato, a obra demonstra que a efetividade das instituições participativas passa por questões conceituais e metodológicas, inclusive do que significa efetividade e de como mensurá-la. Foi exatamente nas dificuldades apresentadas para se analisar a efetividade que se explicitou duas contribuições importantes: a qualidade dos processos participativos e a multiplicidade de "perspectivas, enfoques, estratégias e técnicas de análise" (PIRES et al., 2011, p. 361), que viabilizaram as análises dos resultados das políticas públicas relacionadas às instituições participativas.

Os trabalhos sobre as instituições participativas, como os conselhos municipais, foram sofisticados nos últimos anos. Mesmo assim, as análises efetuadas pela literatura especializada priorizam o funcionamento interno dos conselhos ou apenas ressaltam as relações com o Executivo municipal. Esse quadro pode ser observado a partir do levantamento efetuado por Luciana Tatagiba (2005, p. 211), que acrescenta à lista de entraves internos a "ambígua inserção no conjunto da institucionalidade" e a "questão da existência e efetividade dos fundos". 
Neste artigo, nossa proposição não é negar os problemas propostos pela literatura, pois concordamos que as pesquisas devem ser realizadas sob diversas perspectivas. Acreditamos que nossa contribuição neste trabalho seja agregar ao debate uma perspectiva que não busca analisar o problema da efetividade dentro do âmbito municipal, mas que amplia a compreensão da efetividade dos conselhos. Abordamos, ao nosso ver, um aspecto central: a coordenação federativa das políticas públicas, que está vinculada à pesquisa de Tatagiba (2005) no que se refere ao trato dos fundos destinados às políticas sociais.

Nossa abordagem partiu de um consenso nas análises dos conselhos municipais de que recursos federais foram responsáveis pela maciça instituição, disseminação e manutenção dos conselhos municipais de temáticas específicas, como ilustrado nos exemplos clássicos da saúde, da assistência social e da educação. Os fundos federais funcionariam como uma espécie de incentivo seletivo (OLSON, 1999) buscando a adesão dos municípios para a resolução de um problema de ação coletiva das políticas públicas coordenadas em escala nacional. Buscamos, aqui, aprofundar a compreensão desse processo e de como a transferência dos recursos pode estar relacionada a uma dimensão da efetividade dos conselhos municipais. Por isso, é importante estabelecer o limite da presente abordagem, ressaltando o apontamento de Alexander Vaz e Roberto Pires (2011, p. 248), no qual dizem que determinados conselhos, como cultura, meio ambiente, política urbana, difundiram-se mesmo não envolvendo "repasses de recursos aos municípios".

Em termos mais objetivos, este artigo trata dos conselhos municipais que recebem recursos ou outros incentivos para aderir a determinadas políticas. Porém, frisamos que, além dos municípios que são contemplados com verbas e incentivos federais, existem aqueles que recebem recursos dos seus respectivos estados, que também possuem interesse em implementar políticas coordenadas, a seu modo, em seus territórios. Para tanto, utilizam, entre outros instrumentos, o repasse da cota-parte para os municípios, do principal tributo de competência dos estados, que é o Imposto sobre Operações relativas à Circulação de Mercadorias e sobre Prestações de Serviços de Transporte Interestadual, Intermunicipal e de Comunicação (ICMS).

Essa questão ficou clara na análise do número de Conselhos de Proteção ao Patrimônio Cultural em Minas Gerais e a lei de repasse do ICMS (LIRA, AZEVEDO e BORSANI, 2014). Ainda não há um estudo que vincule o número de Conselhos de Meio Ambiente às leis estaduais de repasses deste tributo. Entretanto, no Brasil, 17 estados já contam com o ICMS Ecológico. São a conselhos instituídos por incentivo da esfera federal ou estadual ao qual este artigo refere. De qualquer modo, a mesma lógica pode servir parcialmente para os conselhos que surgem por uma agenda municipal, por um possível crescimento incremental de conselhos temáticos ou por outras causas ${ }^{1}$. 


\section{Coordenação de políticas públicas, federalismo e conselhos municipais}

Os conselhos são "instituições híbridas nas quais há participação do Executivo e de atores da sociedade civil relacionados com a área temática na qual o conselho atua" (AVRITZER, 2006, p. 39). Eles têm se multiplicado pelo Brasil como gestores das mais diversas políticas e representam uma das principais experiências de gestão democrática. O formato dos conselhos municipais gestores congrega elementos da autonomia, da descentralização administrativa, da coordenação e da inserção da participação popular na gestão das políticas públicas, com o objetivo de uma maior efetividade em sua implementação e controle (CUNHA, 1997, p. 96).

Os argumentos centrais que utilizamos para analisar o modus operandi dos conselhos foram de matriz olsoniana, com destaque para as obras Big Bills Left on the Sidewalk (OLSON, 1996) e A lógica da ação coletiva (Idem, 1999). A primeira obra critica a abordagem de Ronald Coase (1960) em relação ao custo de transação e as trocas voluntárias, uma vez que, para Mancur Olson (1996), a barganha espontânea, sem regulação não é capaz de gerar a eficiência necessária para o desenvolvimento de instituições econômicas e políticas que cuidem de grandes somas, contratos a longo prazo e outras operações mais complexas do mercado e da política. Para o autor, são necessárias instituições que coordenem o desenvolvimento econômico e social.

O problema é que as quantias realmente altas não podem ser coletadas por meio de ações individuais não coordenadas. Somente podem ser obtidas mediante a cooperação eficiente de muitos milhões de trabalhos especializados e outros insumos: ou seja, só podem ser alcançadas se um vasto conjunto de ganhos com a especialização e o comércio for concretizado (OLSON, 1996, p. 22).

Em um país como o Brasil, de proporção continental, as políticas públicas consideradas essenciais para o Estado e para a sociedade, como educação, saúde e assistência social, necessitam de uma gestão coordenada para seu desenvolvimento e controle. Do contrário, os esforços isolados de entes federativos poderiam gerar grandes custos e resultados ineficientes, como redundância de gastos, duplicidade de ações e relações predatórias. Também, a falta de um padrão de provimento dos bens públicos pode redundar na impossibilidade do controle da gestão administrativa.

O federalismo brasileiro possui a singularidade de colocar o município como ente federativo e, portanto, tem autonomia federativa. Isto é, uma autonomia política, administrativa, financeira e tributária que só pode ser limitada pela Constituição ${ }^{2}$. A autonomia federativa é o campo de competência constitucional em relação ao qual um ente federativo não pode interferir na competência de outro. O problema é que a autonomia pode levar a uma falta de coordenação, necessária em políticas públicas mais amplas e universais. Gera-se, assim, um grave problema de avaliação global de efetividade e mecanismos de manutenção de accountability horizontal 
enquanto rede institucional. Em outras palavras, a questão que se coloca é: como alcançar a cooperação da União, dos 26 Estados, do Distrito Federal e dos 5.570 municípios em torno de um leque de políticas públicas, sendo cada um desses entes autônomos?

Para o que se pretende neste artigo, partiremos do entendimento que as políticas públicas coordenadas de tipo federativo são aquelas de provisão de serviços públicos ou políticas de regulação que, no seu desenho institucional, preveem a atuação efetiva de dois ou mais entes federativos, coma preponderância (fator coordenativo) de um ou mais na formulação das diretrizes dessas políticas, e a posse de mecanismos de incentivos seletivos ou enforcement que possibilite a indução da cooperação dos outros entes na execução.

A segunda obra de Olson (1999), A lógica da ação coletiva, cuja análise é mais conhecida, demonstra exatamente que as dificuldades e obstáculos para a ação coletiva em grandes grupos (grupos latentes) de indivíduos em busca de bens públicos inviabilizam a ação conjunta. São três as razões para a deserção: a observação da participação como não necessária para alcançar o bem público; a impossibilidade de coerção; ea provisão do bem público não poder ser excluída dos membros do grupo. Assim, é possível não arcar com o custo da participação e, mesmo assim, beneficiar-se da ação coletiva realizada pelos outros membros do grupo. Esse indivíduo é caracterizado como freerider ou carona.

A fim de modificar o equilíbrio da participação de uma ação de deserção para a cooperação em grandes grupos, Olson (Idem) apresenta os incentivos seletivos como indutores da participação. Os incentivos seletivos se caracterizam por serem distribuídos apenas a aqueles que participam da ação, que cooperam para o alcance do bem público. Funcionam como um mecanismo de estímulo à cooperação dos atores sociais e econômicos. São comumente usados como forma de induzir à participação a uma determinada ação coletiva. Por isso, necessitam de coordenação.

A instituição de fundos federais como incentivos seletivos, ao estabelecer requisitos voltados para a gestão local para seu recebimento, foi um fator fundamental para a introdução das experiências dos conselhos gestores municipais no Brasil. Esses conselhos consolidados como uma inovação institucional da Constituição Federal de 1988 e das leis infraconstitucionais que a regulamentam tornaram-se obrigatórios (TATAGIBA, 2002, p. 50).

É certo que os conselhos não precisam estar vinculados a um fundo federal ou de qualquer outro tipo para existir, visto que o município possui autonomia administrativa e que as legislações em relação à formação dos conselhos podem ser bem distintas. Porém, foram os conselhos que se ligam a fundos - principalmente os de saúde, de assistência social e de educação - que se apresentaram em maior número, comparados a outras áreas temáticas como turismo, patrimônio cultural e transporte. 
Com efeito, pode-se dizer que os incentivos seletivos, na forma de "recursos institucionais de que dispõe o Governo Federal para induzir as decisões dos governos subnacionais" (ARRECTHE, 2004, p. 18), são instrumentos para a consolidação e manutenção dos conselhos. São esses incentivos que possibilitam a existência do que chamamos de políticas públicas coordenadas de tipo federativo, com a adesão dos entes subnacionais.

A Tabela 1 mostra a variação absoluta do número de conselhos municipais, medido em momentos distintos, a partir dos levantamentos efetuados pela pesquisa Perfil dos Municípios Brasileiros do Instituto Brasileiro de Geografia e Estatística (IBGE, 2001, 2009, 2011, 2013, 2014). O ano base de coleta dos dados foi 2001, com intervalos distintos para cada uma das categorias dos três conselhos sob análise do IBGE. A série obtida junto à Pesquisa de Informações Básicas Municipais (Idem, 2001, 2009, 2011, 2013 e 2014) sobre os conselhos municipais não é homogênea para todos os conselhos, como observado na tabela.

Tabela 1: Número de municípios, por grandes regiões, com Conselhos Municipais de Saúde, Assistência Social e Educação (2001, 2009, 2011, 2013 e 2014)

\begin{tabular}{|c|c|c|c|c|c|c|c|c|c|c|c|c|c|c|c|c|c|c|c|c|}
\hline \multirow{3}{*}{ Regiōes } & \multirow{3}{*}{$\begin{array}{l}\text { Número de } \\
\text { municípios } \\
(2013- \\
2014)\end{array}$} & \multicolumn{19}{|c|}{ Conselhos } \\
\hline & & \multicolumn{7}{|c|}{ Saúde } & \multicolumn{6}{|c|}{ Assistência Social } & \multicolumn{6}{|c|}{ Educação } \\
\hline & & 2001 & 2009 & 2011 & 2013 & 2014 & $\begin{array}{c}\text { Var } \\
\%\end{array}$ & $\% \mathrm{~T}$ & 2001 & 2005 & 2012 & 2013 & $\begin{array}{c}\text { Var } \\
\%\end{array}$ & $\% \mathbf{T}$ & 2001 & 2009 & 2011 & 2014 & $\begin{array}{c}\text { Var } \\
\%\end{array}$ & $\% \mathrm{~T}$ \\
\hline Brasil & 5.570 & 5.426 & 5.417 & 5.553 & 5.553 & 5.556 & 2,40 & 99,8 & 5.178 & 5.497 & 5.527 & 5.562 & 7,42 & 99,9 & 4.072 & 4.403 & 4.718 & 4.874 & 19,70 & 87,5 \\
\hline Norte & 450 & 441 & 430 & 446 & 448 & 447 & 1,36 & 99,3 & 420 & 445 & 444 & 449 & 6,90 & 99,8 & 282 & 262 & 292 & 320 & 13,48 & 71,1 \\
\hline Nordeste & 1.794 & 1.731 & 1.720 & 1.788 & 1.790 & 1.790 & 3,41 & 99,8 & 1.644 & 1.774 & 1.783 & 1.792 & 9,00 & 99,9 & 1.183 & 1.359 & 1.507 & 1.568 & 32,54 & 87,4 \\
\hline Sudeste & 1.668 & 1.637 & 1.635 & 1.667 & 1.666 & 1.668 & 1,89 & 100,0 & 1.534 & 1.643 & 1.656 & 1.668 & 8,74 & 100,0 & 1.353 & 1.455 & 1.501 & 1.528 & 12,93 & 91,6 \\
\hline Sul & 1.191 & 1.172 & 1.178 & 1.187 & 1.188 & 1.190 & 1,54 & 99,9 & 1.141 & 1.170 & 1.182 & 1.187 & 4,03 & 99,7 & 903 & 973 & 1.046 & 1.084 & 20,04 & 91,0 \\
\hline $\begin{array}{l}\text { Centro- } \\
\text { Oeste }\end{array}$ & 467 & 445 & 454 & 465 & 461 & 461 & 3,60 & 98,7 & 439 & 465 & 462 & 466 & 6,15 & 99,8 & 351 & 354 & 372 & 374 & 6,55 & 80,1 \\
\hline
\end{tabular}

Fonte: Elaboração dos autores.

Algumas análises podem ser feitas a partir desses dados. Primeiramente, vale lembrar que as três políticas em questão são condicionadas, ou seja, o repasse de recursos do Governo Federal para as respectivas pastas somente é efetivada pela presença dos conselhos municipais. Portanto, a transferência de recursos como um incentivo seletivo é uma variável relevante para a análise da variação.

Considerando o primeiro intervalo, o maior espaçamento da pesquisa é de oito anos - com exceção dos Conselhos de Assistência Social, cujo intervalo é de quatro anos. Após o segundo ciclo da pesquisa do IBGE, o intervalo de análise tornou-se menor.

O Gráfico 1 ilustra a evolução percentual da existência dos conselhos para o último ano pesquisado pelo IBGE. A média dos percentuais dos Conselhos de Saúde e Assistência Social, presentes nos municípios das cinco regiões brasileiras, chega próximo à totalidade, acima de 
99,6\% para os dois casos. Já o Conselho de Educação apresenta uma média menor, de 84,8\%, em todas as regiões do Brasil. A região Norte apresenta o menor número de municípios com Conselhos de Educação, com 71,1\% dos municípios pesquisados em 2014. No caso da educação, a variação mais acentuada em relação ao quantitativo dos conselhos alia-se à coexistência nos municípios dos Conselhos de Controle e Acompanhamento do Fundo de Manutenção e Desenvolvimento da Educação Básica (Fundeb), que configuram elementos de coordenação federativa e funcionam como um dos indutores do processo de descentralização dessa política (SOUZA, 2018; GOMES, 2009), ocupando 98,5\% dos municípios brasileiros (IBGE, 2014). Vale ressaltar que esse fundo, por determinação legal, tem o seu funcionamento previsto até o final de 2020, o que coloca em xeque um importante mecanismo de financiamento da política educacional. Tais questões são discutidas no âmbito legislativo.

Gráfico 1: Evolução percentual dos Conselhos Municipais de Saúde, Assistência Social e Educação para o último ano da pesquisa em relação ao total de municípios
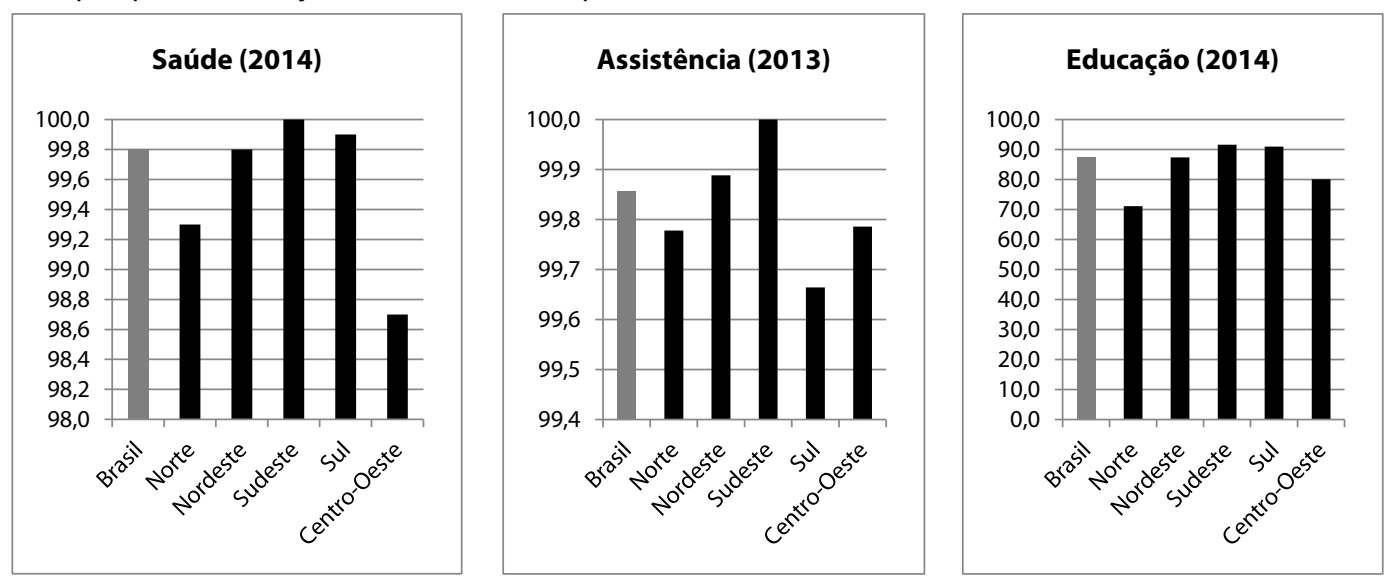

Fonte: Elaboração dos autores.

O Gráfico 2 ilustra a variação percentual entre o primeiro e o último ano dos respectivos conselhos por região do país. A menor média nacional $(2,40 \%)$ é relativa ao número de Conselhos de Saúde que foram criados ao longo dos anos de pesquisa. Isso significa que, para essa política, desde o início da série, quase a todos dos municípios já contavam com eles. A região que apresentou maior crescimento no número de municípios com Conselhos de Saúde foi o CentroOeste que, entretanto, partiu de um número inferior às demais regiões. No caso dos Conselhos de Assistência Social, a variação percentual média nacional ficou em 7,04\%, significativamente superior à média da criação dos Conselhos de Saúde. Por fim, o Gráfico 2 mostra a falta de uniformidade na criação dos Conselhos de Educação nos municípios brasileiros. As variações percentuais na sua criação chegam a extremos, com uma elevação de 32,54\% na região Nordeste e uma de 6,55\% na região Centro-Oeste, representando uma variação média nacional de 17,54\%. 
Gráfico 2: Variação percentual dos Conselhos Municipais de Saúde, Assistência Social e Educação: primeiro para o último ano da pesquisa
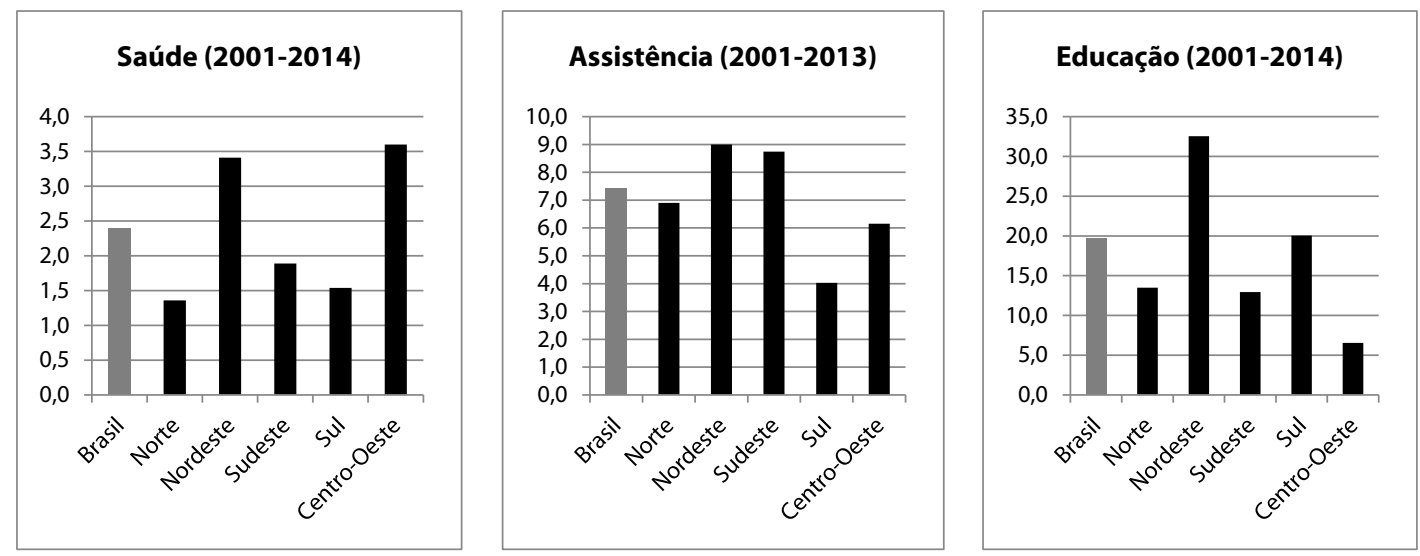

Fonte: Elaboração dos autores.

A partir dos dados, infere-se que a coordenação assume um papel importante quando observada a eficácia em relação à implementação dos instrumentos de práticas participativas. Isso se torna mais presente no caso dos conselhos municipais ligados a incentivos seletivos nacionais, em que há a exigência formal para o repasse de recursos para a política local. Os resultados são diferentes daqueles nas quais a autonomia municipal federativa não foi tocada pela União, como questões urbanas e ambientais observadas na Tabela 2.

Tabela 2: Número de municípios, por grandes regiões, com Conselhos Municipais de Meio Ambiente e Política Urbana (2001, 2009, 2012 e 2013)

\begin{tabular}{|c|c|c|c|c|c|c|c|c|c|c|}
\hline \multirow{2}{*}{ Regiões } & \multirow{2}{*}{$\begin{array}{c}\text { Número de } \\
\text { municípios }\end{array}$} & \multicolumn{9}{|c|}{ Conselhos } \\
\cline { 3 - 13 } & & $\mathbf{2 0 0 1}$ & $\mathbf{2 0 0 9}$ & $\mathbf{2 0 1 2}$ & $\mathbf{2 0 1 3}$ & $\mathbf{\%}$ & $\mathbf{2 0 0 1}$ & $\mathbf{2 0 0 9}$ & $\mathbf{2 0 1 2}$ & $\mathbf{\%}$ \\
\hline Brasil & $\mathbf{5 . 5 7 0}$ & $\mathbf{1 . 6 1 5}$ & $\mathbf{3 . 1 2 4}$ & $\mathbf{3 . 5 4 0}$ & $\mathbf{3 . 7 8 4}$ & $\mathbf{6 7 , 9}$ & $\mathbf{3 3 4}$ & $\mathbf{9 8 1}$ & $\mathbf{1 . 2 3 1}$ & $\mathbf{2 2 , 1}$ \\
\hline Norte & 450 & 83 & 214 & 272 & 311 & 69,1 & 20 & 64 & 94 & 20,9 \\
\hline Nordeste & 1.794 & 256 & 649 & 725 & 793 & 44,2 & 48 & 189 & 209 & 11,6 \\
\hline Sudeste & 1.668 & 655 & 1.185 & 1.319 & 1.392 & 83,5 & 91 & 300 & 362 & 21,7 \\
\hline Sul & 1.191 & 471 & 798 & 896 & 934 & 78,4 & 152 & 348 & 479 & 40,2 \\
\hline $\begin{array}{c}\text { Centro- } \\
\text { Oeste }\end{array}$ & 467 & 150 & 278 & 328 & 354 & 75,8 & 23 & 80 & 87 & 18,6 \\
\hline
\end{tabular}

Fonte: Elaboração dos autores.

Como não existe um fundo federal ou estadual voltado para o desenvolvimento de uma política sistemática de urbanismo, apesar de uma tendência de crescimento visível, o número de conselhos que tratam do tema ainda é pequeno se comparado à criação, ao desenvolvimento e à manutenção dos Conselhos de Saúde, de Assistência Social e de Educação. Em termos de média, pelos dados coletados pelo IBGE (2001, 2009, 2012 e 2013), tem-se que os Conselhos de Meio Ambiente espalhados pelo país ocupam menos que 70\% dos municípios, com destaque para a 
região Sudeste que possui $83,5 \%$ dos municípios com conselhos setoriais. A região Nordeste vai para o outro extremo, com 44,2\% dos seus municípios com Conselhos do Meio Ambiente. Já o Conselho de Política Urbana, o outro exemplo analisado, tem em média pouco mais de $20 \%$ dos seus municípios com conselhos específicos para esse setor. A região Nordeste também puxa a média para baixo, com apenas $11,6 \%$ dos seus municípios com conselhos voltados para política pública. O Gráfico 3 ilustra esses dados.

Gráfico 3: Variação percentual dos Conselhos Municipais de Meio Ambiente e Política Urbana para o último ano da pesquisa em relação ao total de municípios
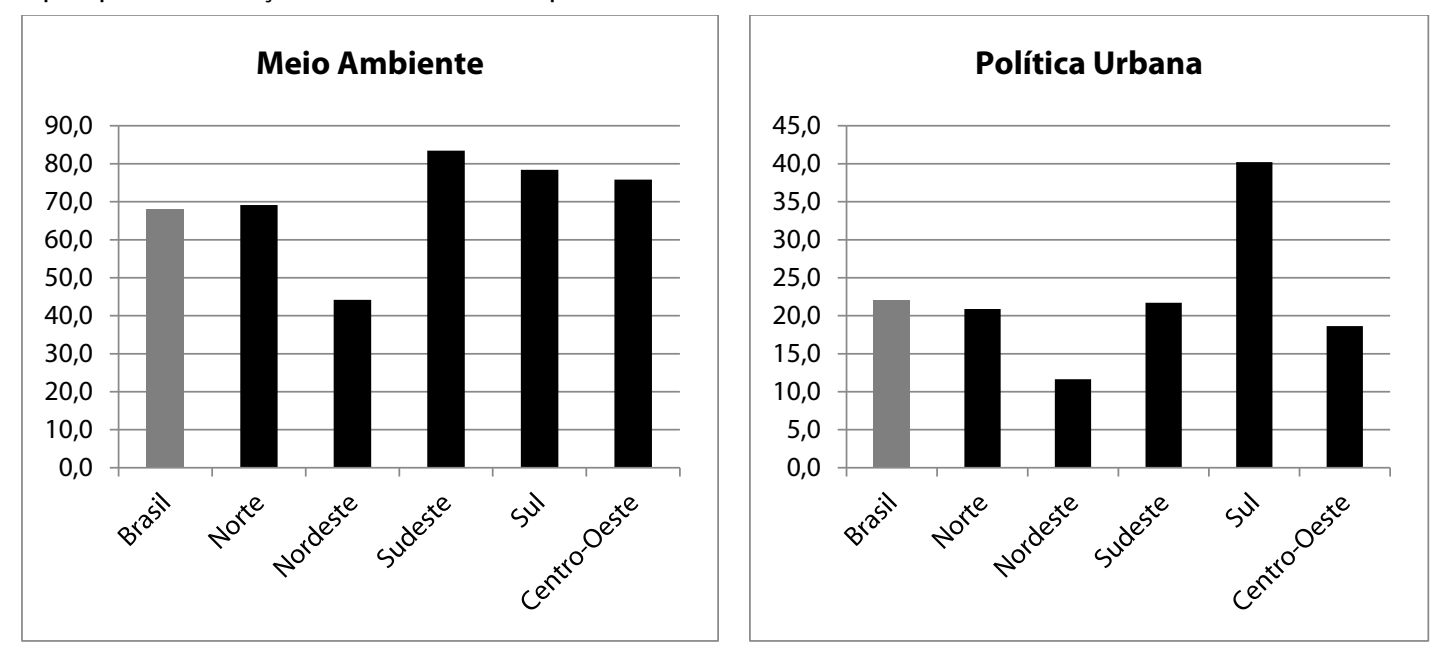

Fonte: Elaboração dos autores.

No entanto, o que pode explicar o aumento do número de Conselhos de Meio Ambiente em determinados estados membros ou a concentração de Conselhos de Patrimônio Cultural em Minas Gerais? Na Tabela 3, destacam-se os Conselhos Municipais de Patrimônio Cultural espalhados pelo país. Nota-se um número expressivo desses conselhos setoriais em Minas Gerais.

Tabela 3: Número de municípios, por grandes regiões, com Conselho Municipal de Patrimônio Cultural, em 2006 e 2014

\begin{tabular}{|l|c|c|c|c|c|c|c|c|}
\hline \multirow{2}{*}{ Regiões } & \multicolumn{4}{|c|}{ Municípios/Conselhos em 2006 } & \multicolumn{4}{c|}{ Municípios/Conselhos em 2014 } \\
\cline { 2 - 10 } & $\begin{array}{l}\text { Número de } \\
\text { municípios }\end{array}$ & $\begin{array}{c}\text { Municípios } \\
\text { com Conselho } \\
\text { de Patrimônio }\end{array}$ & $\begin{array}{c}\text { \%T } \\
\text { Municípios }\end{array}$ & $\begin{array}{c}\text { \%T Municípios } \\
\text { com conselho }\end{array}$ & $\begin{array}{c}\text { Número de } \\
\text { municípios }\end{array}$ & $\begin{array}{c}\text { Municípios } \\
\text { com Conselho } \\
\text { de Patrimônio }\end{array}$ & $\begin{array}{c}\text { \%T } \\
\text { Municípios }\end{array}$ & $\begin{array}{l}\text { \%T Municípios } \\
\text { com conselho }\end{array}$ \\
\hline Brasil & $\mathbf{5 . 5 6 4}$ & $\mathbf{7 4 1}$ & $\mathbf{1 3 , 3 2}$ & $\mathbf{1 0 0 , 0 0}$ & $\mathbf{5 . 5 7 0}$ & $\mathbf{1 . 0 3 4}$ & $\mathbf{1 8 , 5 6}$ & $\mathbf{1 0 0 , 0 0}$ \\
\hline Norte & 449 & 6 & 1,33 & 0,81 & 450 & 14 & 3,11 & 1,35 \\
\hline Nordeste & 1.793 & 24 & 1,34 & 3,24 & 1.794 & 81 & 4,52 & 7,83 \\
\hline Sudeste & 1.668 & 619 & 37,11 & 83,54 & 1.668 & 808 & 48,44 & 78,14 \\
\hline Minas Gerais & 853 & 517 & 60,61 & 69,77 & 853 & 675 & 40,47 & 65,28 \\
\hline Sul & 1.188 & 79 & 6,65 & 10,66 & 1.191 & 105 & 8,82 & 10,15 \\
\hline Centro-Oeste & 466 & 13 & 2,79 & 1,75 & 467 & 26 & 5,57 & 2,51 \\
\hline
\end{tabular}

Fonte: Elaboração dos autores. 
A coordenação de políticas públicas pelos estados ocorre, em boa medida, com o mesmo critério da União, utilizando o mecanismo dos incentivos seletivos. No caso dos estados, os incentivos podem decorrer, sobretudo, por meio do uso de parte do repasse do ICMS, no qual o estado membro é capaz de regulamentar parte da distribuição. Trata-se, portanto, de um dispositivo constitucional e legal que pode exprimir a capacidade de coordenação de cada estado no que se refere às políticas públicas subnacionais ${ }^{3}$.

Em Minas Gerais, por exemplo, o equivalente a 1\% da parcela do ICMS, regulamentado por lei estadual, é destinado aos municípios que se adéquam às diretrizes da política de proteção ao patrimônio cultural. Dentre outras exigências, a legislação estadual estabelece pontuação ao município que possui conselho municipal para esse fim. Dessa forma, a busca pelos recursos do ICMS explica a disparidade entre o número de Conselhos de Proteção ao Patrimônio em Minas Gerais em relação não apenas à região Sudeste, mas também a outros estados da federação (LIRA, AZEVEDO e BORSANI, 2014, p. 133).

\footnotetext{
Aqui se encontra a nova questão resultante do federalismo conformado na redemocratização: a descentralização depende agora, diversamente do que ocorria no regime centralizador e autoritário, da adesão dos níveis de governo estadual e municipal. Por isso, o jogo federativo depende hoje de barganhas, negociações, coalizões e induções das esferas superiores de poder, como é natural em uma federação democrática. Em suma, seu sucesso associa-se a processos de coordenação intergovernamental (ABRUCIO, 2005, p. 49).
}

Nesse sentido, para os financiadores (União e estados membros) das políticas coordenadas de tipo federativo, a participação da sociedade civil dentro dos conselhos possui um papel estratégico de controle. Os conselhos utilizados como instrumentos de controle das políticas públicas possuem, em tese, a vantagem de diminuição do custo de fiscalização e do aumento do monitoramento da efetividade da implementação, uma vez que os representantes da sociedade teriam o interesse em participar da formulação das diretrizes e acompanhamento de políticas públicas cujo tema lhes é caro. Nesse sentido, a forma como se estrutura a relação entre participação e representação de interesses dentro dos conselhos possui forte impacto na maneira como se processa a deliberação e o controle (SALLES e AZEVEDO, 2013).

As políticas de tipo federativa desenhadas dessa forma possibilitam que os entes federativos coordenadores não necessitem contratar ou deslocar funcionários para um controle ostensivo destas políticas em cada um dos municípios. Esse tipo de monitoramento é conhecido segundo a tipologia de Mathew McCubbins e Thomas Schwartz (1984) como "patrulha de polícia”.

Semelhante ao uso de patrulhas policiais propriamente ditas, a supervisão, do tipo patrulhamento de polícia, é comparativamente centralizada, ativa e direta: por iniciativa própria (...). As atividades de uma 
agência podem ser de supervisão por diversos meios, tais como leitura de documentos, solicitação de estudos científicos, condução de pesquisas de campo e realização de audiências para interrogar funcionários e cidadãos afetados (MCCUBBINS e SCHWARTZ, 1984, p. 166).

Patrulha de polícia está associada a uma fiscalização sistemática de custos mais elevados, no qual uma agência deve agir em relação a todo desvio potencial que possa vir a ocorrer nos programas governamentais nos quais os burocratas sob sua supervisão atuam (MELO, 2001, p. 61).

No caso dos conselhos, funcionam como patrulha de polícia em relação à política local. Em relação aos entes centrais, realizam o monitoramento por meio de um controle indireto ou "alarme de incêndio", que se refere ao "monitoramento seletivo, de custo eficiente, voltado para a identificação dos desvios ou comportamento oportunista da burocracia que são denunciados pela base parlamentar dos congressistas" (Idem).

\footnotetext{
Semelhante ao uso de alarmes de incêndio reais, a supervisão, do tipo alarme de incêndio, é menos centralizada e envolve menor intervenção ativa e direta do que a supervisão do tipo patrulhamento de polícia: mais do que examinar uma amostra de decisões administrativas, buscando violações de metas legislativas, o Congresso estabelece um sistema de regras, procedimentos e práticas informais que permitem aos cidadãos individuais e grupos de interesse organizados examinar decisões administrativas (às vezes em perspectiva), cobrar de agências executivas, tribunais e do próprio Congresso (MCCUBBINS e SCHWARTZ, 1984, p. 166).
}

Ao avaliar a estrutura e o desenho institucional de coordenação das políticas públicas de tipo federativo, pode-se observar sob o enfoque da eficácia que esta teve sucesso, pelo menos no que se refere à criação e à manutenção dos conselhos nos municípios, como observado principalmente na Tabela 1. Em outras palavras, os sistemas nacionais, em relação à criação de uma rede formal entre os entes federados via incentivos seletivos, concretizaram-se.

Todavia, não é incomum ouvir a afirmação dos atores que trabalham ou estudam o tema de que o conselho não funciona. Essa é uma questão que difere da eficácia ${ }^{4}$ do desenho institucional do sistema que se logrou colocar em prática no Brasil. Quando escuta-se que os conselhos não funcionam, trata-se de uma avaliação de efetividade, entendida como os resultados políticos e sociais da ação dos conselhos, de como os cidadãos envolvidos em determinada temática enxergam a participação e a representação dentro dos conselhos, bem como o real poder em intervir, efetivar e fiscalizar a política ao qual está vinculado. E, por último, qual importância que a prefeitura atribui às decisões colegiadas do conselho.

Assim, se as políticas federativas lograram alcançar eficácia na instituição de seus instrumentos participativos, a efetividade é colocada em xeque. Nesse sentido, o arcabouço teórico sobre accountability pode auxiliar a compreender o escopo das instituições participativas e as expectativas que se originam delas. E, pensando na trajetória de construção institucional de base participativa, 
reforçam-se os próprios mecanismos de accountability. No entanto, esse constructo democrático pode se desequilibrar em cenários adversos. Autores como Scott Mainwaring e Fernando Bizzarro (2019, p. 8) apontam que democracias como a brasileira, apesar dos avanços observados nas últimas décadas, "vem enfrentando grandes desafios políticos". Tais perspectivas realçam os apontamentos de Yascha Mounk (2019), ao considerar que uma recessão democrática pode afetar as democracias liberais em todo o mundo com a emergência de governos populistas conservadores.

Leonardo Avritzer (2018) chama atenção para o fato de que os retrocessos referentes às instituições democráticas no Brasil têm início antes mesmo da eleição de Jair Bolsonaro para a presidência em 2018. Segundo o autor, as manifestações de junho de 2013 impulsionam as narrativas de ataques aos atores e às políticas institucional e partidária. Nesse cenário, o que se observou foi a emergência de uma posição conservadora, inclusive contrária à ideia de participação. Tal guinada é reforçada com o impeachment da presidente Dilma Rousseff e a posse de Michel Temer em 2016. Nesse contexto, é editada a medida provisória nº 726 (BRASIL, 2016), que extingue o Ministério das Mulheres, da Igualdade Racial, da Juventude e dos Direitos Humanos, importante conquista dos movimentos sociais. Tem-se, assim, os primeiros passos na direção contrária das instituições participativas, pois

(...) o impeachment e a Medida Provisória no 726 representaram um movimento de retorno no pêndulo democrático descrito, no que diz respeito à relação entre a vontade do eleitorado e as políticas públicas, pêndulo este que geralmente se movimenta quando as forças do mercado se sentem contrariadas (AVRITZER, 2018, p. 286).

A radicalização das ações voltadas para suprimir o processo participativo é fortalecida com a vitória de Jair Bolsonaro, que representa a ascensão da extrema direita. Esse fortalecimento pode ser observado, por exemplo, na edição da medida provisória $n^{\circ} 870$, de $1^{\circ}$ de janeiro de $2019^{5}$, que extinguiu o Conselho Nacional de Segurança Alimentar e Nutricional (Consea), órgão de assessoramento à Presidência da República e de caráter consultivo, mas que lida com a questão da insegurança alimentar e nutricional, "que afeta de forma desigual os diferentes segmentos da sociedade", cuja complexidade só se pode compreender, a partir da participação social, que foi suprimida por essa norma (CASTRO, 2019, p. 2).

A supressão dos mecanismos de participação social, que veio no bojo do argumento de ampliar a eficiência e diminuir os custos da máquina pública, também pode ser observada na edição do decreto no 9.759, de 11 de abril de 2019 (BRASIL, 2019) ${ }^{6}$. Nessa direção, o atual ministro da Casa Civil, em entrevista coletiva, instituiu o chamado revogaço com a intenção de diminuir grande parte dos cerca de 700 órgãos federais colegiados. 
Por fim, nesses momentos de fragilidade institucional, a ideia de agências de accountability que garantem o funcionamento das próprias instituições e com mecanismos eficientes de autocontrole se mostra cada vez mais importante.

\section{Accountability horizontal e a distribuição de responsabilidades entre os entes federativos}

A argumentação principal que utilizamos não é inédita e tem como norte o seminal artigo de Guillermo O'Donnell (1998), “Accountability horizontal e novas poliarquias”. O argumento do autor, em resumo, pode ser colocado da seguinte forma: nas novas poliarquias, que incluem o Brasil, havia a esperança de que o regime democrático fosse uma variável suficiente para que antigas gramáticas de relações políticas e sociais tidas como perversas, a exemplo do clientelismo, não perdurassem. Entretanto, segundo o autor, isso não ocorreu.

O diagnóstico de O’Donnell é que, mesmo as novas democracias possuindo as características que as enquadram como poliarquias ${ }^{7}$, a elas falta a dimensão horizontal de accountability democrática. Apesar de necessário um regime eleitoral representativo com todas as suas regras formais para escolha de representantes, deduz-se que a democracia depende do alcance e da extensão da sua rede institucional de accountability horizontal para estabelecer qualidade democrática. Outro aspecto importante é denominado accountabilitysocietal, que trata do espaço institucional dado à sociedade para o controle das ações - ou omissões - dos agentes públicos.

Com a delegação de competências e responsabilização dos agentes públicos, a rede institucional de accountability incrementa a viabilidade e a qualidade da democracia. Sob essa perspectiva, torna-se relevante a noção de accountability democrática e, por conseguinte, os modelos vertical e horizontal de accountability de Guillermo O’Donnell (1998).

Accountability vertical engloba accountability eleitoral, segundo a qual a responsabilização política é dada no momento da eleição, premiando ou punindo o político ou o partido por meio do voto (O’DONNELL, 1998). Já accountability societal seria um mecanismo "pelo qual cidadãos, meios de comunicação social e associações civis buscam aplicar boas práticas aos agentes públicos" (SCHEDLER et al., 1999, p. 3).

O’Donnell explicita a ideia de accountabilitysocietal inserida em accountability vertical:

Eleições, reivindicações sociais que possam ser normalmente proferidas, sem que se corra o risco de coerção, e cobertura regular pela mídia ao menos das mais visíveis dessas reivindicações e de atos supostamente ilícitos de autoridades públicas são dimensões do que chamo de accountability vertical. São 
ações realizadas, individualmente ou por algum tipo de ação organizada e/ou coletiva, com referência àqueles que ocupam posições em instituições do Estado, eleitos ou não (O'DONNELL, 1998, p. 28).

Os conselhos municipais, por serem órgãos que possuem como integrantes membros do poder público e da sociedade organizada com a finalidade de debater e elaborar as diretrizes para determinada política pública, acabam por se tornar um espaço institucional privilegiado em seu aspecto informacional. Dessa forma, seus membros são importantes elementos que compõem a dimensão de accountability vertical. Contudo, falta-lhes um mecanismo fundamental da responsabilização, qual seja, a coerção (enforcement). A coerção se encontra na dimensão de accountability horizontal.

\footnotetext{
Accountability horizontal: a existência de agências estatais que têm o direito e o poder legal e que estão de fato dispostas e capacitadas para realizar ações, que vão desde a supervisão de rotina a sanções legais ou até o impeachment contra ações ou emissões de outros agentes ou agências do Estado que possam ser qualificadas de delituosas (O'DONNELL, 1998, p. 40).
}

No Brasil, a rede de accountability horizontal é formada pelo Poder Judiciário, Ministério Público, Tribunais de Contas, Controladorias Internas, entre outros. A relação entre as agências de accountability horizontal e os Conselhos Municipais funciona da seguinte forma: ao se deparar com más práticas administrativas ou o uso ilícito ou ilegal de recursos públicos, os representantes da sociedade integrantes dos conselhos - em tese, mais informados - podem, como um dos mecanismos de controle ou monitoramento, denunciar às agências de accountability horizontal tais irregularidades. Tomam, então, as medidas cabíveis em relação aos órgãos ou agentes estatais responsáveis pela política pública em questão. Desse modo, tem-se que accountability societal possui duas funções essenciais: a primeira trata da capacidade de movimentos sociais, mídia e organizações civis de apontar a más práticas administrativas, influenciando a agenda e as diretrizes das políticas públicas do governo; a segunda função se traduz nos instrumentos que possibilitam que as entidades da sociedade acionem institucionalmente as agências de accountability horizontal.

Isso é demonstrado pelo Tribunal de Contas da União (TCU), que lançou cartilhas direcionadas aos conselheiros de várias temáticas, mas não aos conselhos. A cartilha do TCU (2009), Orientações para conselhos da área de assistência social, coloca a função dos conselhos nos termos de participação e controle. Com essas duas dimensões como os principais elementos de uma parceria com as agências de accountabilityvertical, recentemente é possível observar a continuidade dessa orientação por meio de exemplos como da Cartilha de Orientação para Conselheiros de Saúde do Distrito Federal, realizada pelo Tribunal de Contas do Distrito Federal através da Escola de Contas Públicas (TRIBUNAL DE CONTAS DO DISTRITO FEDERAL, 2018), ou da Cartilha de 
Orientações para Conselheiros de Saúde do Tribunal de Contas da União (TRIBUNAL DE CONTAS DA UNIÃO, 2015). Isso se repete em outras políticas como a de alimentação escolar:

\begin{abstract}
Por que o TCU e o FNDE [Fundo Nacional de Desenvolvimento da Educação] reconhecem que a melhor forma de garantir que os alunos sejam cada vez mais bem atendidos pelo PNAE [Programa Nacional de Alimentação Escolar] é acompanhar de perto a execução do programa. Reconhecem, também, que sozinhos não conseguem acompanhar um programa que alcança todos os municípios do Brasil. E o CAE [Conselho de Alimentação Escolar], por estar bem próximo das escolas, é fundamental para o seu acompanhamento (TCU, 2017, p. 7).
\end{abstract}

Por isso, considera-se essencial o funcionamento da rede de accountability horizontal para o funcionamento das políticas públicas de tipo federativo no Brasil. O conselho não é o parceiro das agências de accountability: são os conselheiros. São eles, bem como as associações e movimentos que representam que funcionam como mecanismos de accountability vertical, nos moldes do monitoramento tipo "alarme de incêndio". Em outras palavras, cabe destacar que é a figura do conselheiro, inserido em um contexto de informação privilegiado no conselho, que tem a capacidade de acionar instâncias superiores por meio dos mecanismos de denúncias.

Assim, o sistema nacional explicita os parâmetros da política pública. Essa centralização possibilita certa homogeneidade nas rotinas e procedimentos da política pública, no qual o conselho é uma arena privilegiada de acesso à informação sobre esses problemas, tendo os conselheiros a capacidade de denunciar os abusos e inconsistências da administração pública.

\title{
Considerações finais
}

O esforço para que as prefeituras e secretarias passem a dar mais importância para os conselhos é uma tarefa fundamental para viabilizar as políticas públicas. A expressão "dar importância" se traduz em ações anteriormente mencionadas, que representam as fragilidades para a efetividade dos conselhos como: garantir o acesso e a transparência das informações, compartilhar o poder na elaboração de pauta do conselho e nos mecanismos democráticos de escolhas de membros e assegurar que o secretário apresente as contas e resultados das políticas ao conselho.

Além da participação popular, os conselhos representam mecanismos de controle das políticas públicas de tipo federativo, de competência da administração pública local, que foi amplamente difundido, quando vinculados a incentivos seletivos, a exemplo dos fundos federais. Como apontado, buscou-se, neste artigo, trazer um enfoque na efetividade dos conselhos municipais, jogando luz no papel dessas instituições participativas no desenho federativo alicerçado na coordenação de políticas públicas nacionais. 
Nesse sentido, a operacionalização da rede de accountabilityhorizontal pelos conselheiros pode ser dimensionada em quatro pontos: a função primordial do conselho é, por meio da gestão participativa, aumentar o diálogo entre o governo e a sociedade para um melhor diagnóstico das várias demandas sociais e implementação de políticas inclusivas e eficientes; a denúncia reiterada pode ser um fator de enfraquecimento da capacidade deliberativa e da consecução de acordos ou consensos possíveis, trazendo uma atmosfera de beligerância ao processo participativo; a ativação das agências de accountability horizontal pelos conselheiros deve ocorrer em situações em que valores e bens fundamentais estão sendo colocado em risco; a mera possibilidade de acionar a rede de accountability horizontal pode ser um instrumento indutor de diálogo e de negociação e limitador de ações unilaterais extremadas. Isso ocorre uma vez que atores com recursos críticos, como o econômico, têm a consciência que se levarem ao limite ou a qualquer custo a imposição de seus interesses, podem ser frustrados pela rede de accountability horizontal. Dessa forma, torna-se mais interessante pensar em ganhos a longo prazo em processo de participação de reiteradas jogadas.

Afinal, em um ambiente institucional em que a participação é coordenada verticalmente, os governos municipais podem dificultar e minar esse tipo de controle. Mas ao mesmo tempo em que o pêndulo da democracia se desloca no sentido de uma regressão das instituições democráticas, os conselhos municipais podem funcionar como arenas de resistência e luta pela democracia fora do âmbito central do poder. Nesse caso, volta-se à ideia de que a participação deve ser construída na medida da necessidade de coordenação das políticas nacionais e da liberdade para a contenção do poder e medidas pouco democráticas.

\section{Notas}

\footnotetext{
1 Estudos de como as políticas participativas, incluindo a criação, a disseminação e a manutenção de conselhos municipais, são difundidas no Brasil ainda são raras. Além de incentivos de financiamento federal e estadual dessas políticas, outros elementos podem exercer um papel relevante na transmissão das experiências participativas, como é o caso das conferências temáticas. Para uma revisão bibliográfica seminal sobre o tema da difusão e transferência de políticas públicas, vide o artigo de Carlos Aurélio Pimenta de Faria (2012).

${ }^{2}$ Art. 18: "A organização político-administrativa da República Federativa do Brasil compreende a União, os Estados, o Distrito Federal e os Municípios, todos autônomos, nos termos desta Constituição (BRASIL, 1988).

${ }^{3}$ Art. 158: "Pertencem aos Municípios: (...) IV. $25 \%$ do produto da arrecadação do imposto do Estado sobre operações relativas à circulação de mercadorias e sobre prestações de serviços de transporte interestadual e intermunicipal e de comunicação. Parágrafo único. As parcelas de receita pertencentes aos Municípios, mencionadas no inciso IV, serão creditadas conforme os seguintes critérios: (...) II - até 1/4, de acordo com o que dispuser lei estadual ou, no caso dos Territórios, lei federal" (BRASIL, 1988).

${ }^{4}$ Os conceitos de eficácia que aqui adotamos é o de Marta Arretche (1998, p. 34), em que "entende-se a avaliação da relação entre objetivos e instrumentos explícitos de um dado programa e seus resultados efetivos. Esta avaliação pode ser feita entre, por exemplo, as metas propostas e as metas alcançadas pelo programa ou entre os instrumentos previstos
} 
para a sua implementação e aqueles efetivamente empregados". Já por efetividade "entende-se o exame da relação entre a implementação de um determinado programa e seus impactos e/ou resultados, isto é, seu sucesso ou fracasso em termo, de uma efetiva mudança nas condições sociais prévias da vida das populações atingidas pelo programa sob avaliação" (Ibid., p. 32).

${ }^{5}$ Vale ressaltar que a medida provisória $n^{\circ} 870$, de $1^{\circ}$ de janeiro de 2019 , foi convertida na lei $n^{\circ} 13.844$, de 18 de junho de 2019.

${ }^{6}$ Vale ressaltar que o decreto, alterado pelo decreto no 9.812, de 30 de maio de 2019, foi objeto de uma Ação Direta de Inconstitucionalidade, impetrado pelo Partido dos Trabalhadores (PT) e, até o momento, por maioria, o STF deferiu parcialmente a liminar, em relação da impossibilidade de extinção, por ato unilateral do Presidente, de órgãos colegiados formalmente instituídos em lei. O exame definitivo da matéria ainda não ocorreu.

${ }^{7}$ As características têm base nos critérios de Robert Dahl (1997). 


\section{Referências}

ABRUCIO, Fernando Luiz Costa; VALERIANO, Mendes Ferreira. Reforma do Estado e o contexto federativo brasileiro. São Paulo: Konrad-Adenauer-Stiftung, 1998.

ABRUCIO, Fernando Luiz Costa. "A coordenação federativa no Brasil: A experiência do período FHC e os desafios do governo Lula”. Revista de Sociologia Política, vol. 24, pp. 41-67, 2005.

ARRETCHE, Marta Teresa da Silva. "Mitos da descentralização: mais democracia e eficiência nas políticas públicas?”. Revista Brasileira de Ciências Sociais, vol. 31, n. 11, pp. 44-66, 1996.

ARRETCHE, Marta Teresa da Silva. "Tendências no estudo sobre avaliação". In: RICO, Elizabeth Melo (org). Avaliação de políticas sociais: Uma questão em debate. São Paulo: Cortez, 1998, pp. 29-39.

ARRETCHE, Marta Teresa da Silva. Estado federativo e políticas sociais: Determinantes da descentralização. Rio de Janeiro/São Paulo: Revan/Fapesp, 2000.

ARRETCHE, Marta Teresa da Silva. "Federalismo e políticas sociais no Brasil: Problemas de coordenação e autonomia". São Paulo em Perspectiva, vol. 18, n. 2, pp. 17-26, 2004.

AVRITZER, Leonardo. "Reforma política e participação no Brasil". In: AVRITZER, Leonardo; ANASTASIA, Fátima (orgs). Reforma política no Brasil. Belo Horizonte: Editora da UFMG, 2006, pp. 35-43.

AVRITZER, Leonardo. "A qualidade da democracia e a questão da efetividade da participação: Mapeando o debate". In: PIRES, Roberto Rocha Coelho (org). Efetividade das instituições participativas no Brasil: Estratégias de avaliação. Brasília: Ipea, 2011, pp. 13-28.

AVRITZER, Leonardo. "O pêndulo da democracia no Brasil: Uma análise da crise 2013-2018". Novos Estudos Cebrap, v. 37, n. 2, pp. 273-289, 2018.

AZEVEDO, Sérgio; SANTOS JR., Orlando Alves; RIBEIRO, Luiz César de Queiroz. Governança democrática e poder local: A experiência dos Conselhos Municipais no Brasil. Rio de Janeiro: Revan, 2004.

BRASIL. Constituição da República Federativa do Brasil. Brasília: Senado, 1988.

BRASIL. Medida provisória nº 726, de 12 de maio de 2016. Brasília: Presidência da República, 2016.

BRASIL. Decreto n 9.759, de 11 de abril de 2019. Brasília: Presidência da República, 2019.

CÂMARA DOS DEPUTADOS. Íntegra do discurso presidente da Assembleia Nacional Constituinte, Dr. Ulysses Guimarães (10'23"), 2006. Disponível em: https://www.camara.leg.br/radio/programas/277285-integra-do-discurso-presidente-daassembleia-nacional-constituinte-dr-ulysses-guimaraes-10-23/

CASTRO, Inês Rugani Ribeiro de. "A extinção do Conselho Nacional de Segurança Alimentar e Nutricional e a agenda de alimentação e nutrição”. Cadernos de Saúde Pública, vol. 35, n. 2, pp. 1-4, 2019. 
COASE, Ronald Harry. "The Problem of Social Cost". Journal of Law and Economics, vol. 3, pp. $1-44,1960$.

CUNHA, Flávio Saliba. "Patrimônio cultural e gestão democrática em Belo Horizonte". Varia Historia, vol. 13, n. 18, pp. 83-98, 1997.

DAHL, Robert Alan. Poliarquia: Participação e oposição. São Paulo: Edusp, 1997.

FARIA, Carlos Aurélio Pimenta. "A difusão de políticas sociais como estratégia de inserção internacional: Brasil e Venezuela comparados”. Interseções, vol. 2, n. 14, pp. 335-371, 2012.

GOMES, Sandra. "Políticas nacionais e implementação subnacional: Uma revisão da descentralização pós-Fundef”. Dados - Revista de Ciências Sociais, vol. 52, n. 3, pp. 659-690, 2009.

IBGE. Perfil dos municípios brasileiros: Pesquisa de informações básicas municipais. Rio de Janeiro: Instituto Brasileiro de Geografia e Estatística (IBGE), 2001.

IBGE. Perfil dos municípios brasileiros: Pesquisa de informações básicas municipais. Rio de Janeiro: Instituto Brasileiro de Geografia e Estatística (IBGE), 2006.

IBGE. Perfil dos municípios brasileiros: Pesquisa de informações básicas municipais. Rio de Janeiro: Instituto Brasileiro de Geografia e Estatística (IBGE), 2009.

IBGE. Perfil dos municípios brasileiros: Pesquisa de informações básicas municipais. Rio de Janeiro: Instituto Brasileiro de Geografia e Estatística (IBGE), 2011.

IBGE. Perfil dos municípios brasileiros: Pesquisa de informações básicas municipais. Rio de Janeiro: Instituto Brasileiro de Geografia e Estatística (IBGE), 2012.

IBGE. Perfil dos municípios brasileiros: Pesquisa de informações básicas municipais. Rio de Janeiro: Instituto Brasileiro de Geografia e Estatística (IBGE), 2013.IBGE. Perfil dos municípios brasileiros: Pesquisa de informações básicas municipais. Rio de Janeiro: Instituto Brasileiro de Geografia e Estatística (IBGE), 2014.

LIRA, Rodrigo Anido; AZEVEDO, Nilo Lima; BORSANI, Hugo. "O sucesso do ICMS cultural revisado: determinantes e obstáculos da política de municipalização para a proteção do patrimônio cultural do estado de Minas Gerais". Vértices, vol. 1, n. 16, pp. 123-145, 2014.

MACHADO, José Ângelo. Políticas públicas descentralizadas e problemas de coordenação: o caso do Sistema Único de Saúde. Tese (Doutorado em Ciências Humanas) - Universidade Federal de Minas, Belo Horizonte, 2007.

MAINWARING, Scott; BIZZARRO, Fernando. "O que aconteceu com as democracias da terceira onda?”. Journal of Democracy, vol. 8, n. 1, pp. 1-25, 2019.

MCCUBBINS, Mathew; SCHWARTZ, Thomas. "Congressional Oversight Overlooked: Police Patrol versus Fire Alarm”. American Journal of Political Science, vol. 28, n. 1, pp. 165-179, 1984.

MELO, Marcus André. “A política da ação regulatória: Responsabilização, credibilidade e delegação”. Revista Brasileira de Ciências Sociais, vol. 16, n. 46,pp. 55-68, 2001.

MOUNK, Yascha. O povo contra a democracia: Por que nossa liberdade corre perigo e como salvá-la. São Paulo: Companhia das Letras, 2019. 
O'DONNELL, Guillermo. “Accountability horizontal e novas poliarquias”. Lua Nova, n. 44, pp. 27-54, 1998.

OLSON, Mancur. "Distinguished on Lecture Economics in Government Big Bills Left on the Sidewalk: Why Some Nations are Rich, and Others Poor". Journal of Economic Perspectives, vol. 10, n. 2, pp. 3-24, 1996.

OLSON, Mancur. A lógica da ação coletiva: Os benefícios públicos e teoria dos grupos sociais. São Paulo: Edusp, 1999.

PIRES, Roberto Rocha Coelho. Efetividade das instituições participativas no Brasil: Estratégias de avaliação. Brasília: Ipea, 2011.

PIRES, Roberto Rocha et al. "Em busca de uma síntese: Ambições comuns e abordagens diversificadas na avaliação da efetividade das instituições participativas". In: PIRES, Roberto Rocha (org). Efetividade das instituições participativas no Brasil: Estratégias de avaliação. Brasília: Ipea, 2011, pp. 347-364.

SALLES, Helena de Motta; AZEVEDO, Nilo Lima de. "Democracia, gestão participativa e patrimônio cultural: O caso do Conselho Municipal de Juiz de Fora". In: AZEVEDO, Paulo; CORRÊA, Elyane Lins (orgs). Estado e sociedade na preservação do patrimônio. Salvador: EdUFBa, 2013, pp. 151-175.

SANTOS JR., Orlando Alves; RIBEIRO, Luiz César de Queiroz; AZEVEDO, Sérgio. Metrópole, desigualdades socioespaciais e governança urbana: Rio de Janeiro, São Paulo, Belo Horizonte, Porto Alegre, Curitiba, Recife e Belém. Questionário Pesquisa realizada no âmbito do Programa de Apoio a Núcleos de Excelência-Pronex, MCT/ Finep, 2001.

SCHEDLER, Andreas; DIAMOND, Larry; PLATTNER, Marc. "Introduction". In: The SelfRestraining State: Power and Accountability in New Democracies.Boulder e Londres: Lynne Rienner Publishers, 1999, pp. 1-12.

SOUZA, Celina. "Intermediação de interesses regionais no Brasil: $\mathrm{O}$ impacto do federalismo e da descentralização”. Dados - Revista de Ciências Sociais, vol. 3, n. 41, pp. 569-592, 1998.

SOUZA, Celina. "Federalismo, desenho constitucional e instituições federativas no Brasil pós1988”. Revista Sociologia e Política, n. 24, pp. 105-121, 2005.

SOUZA, Celina. Coordenação de políticas públicas. Brasília: Enap, 2018.

SMULOVITZ, Catalina; PERUZZOTTI, Enrique. "Societal and Horizontal Controls: Two Cases About a Fruitful Relationship”. In: MAINWARING, Scott; WELNA, Christoper (orgs). Democratic accountability in Latin America. Oxford: Oxford University Press, 2003, pp. 309-332.

TATAGIBA, Luciana. "Os conselhos gestores e a democratização das políticas públicas no Brasil". In: DAGNINO, Evelina (org). Sociedade civil e espaços públicos. São Paulo: Paz e Terra, 2002, pp. 47-103.

TATAGIBA, Luciana. "Conselhos gestores de políticas públicas e democracia participativa: Aprofundando o debate”. Revista de Sociologia e Política do Paraná, n. 25, pp. 209-213, 2005.

TRIBUNAL DE CONTAS DA UNIÃO. Orientações para conselheiros de saúde. Tribunal de Contas da União. Brasília: Tribunal de Contas da União, 2010.

TRIBUNAL DE CONTAS DA UNIÃO. Orientações para conselheiros de saúde. Tribunal de Contas da União. Brasília: Tribunal de Contas da União, 2015. 
TRIBUNAL DE CONTAS DA UNIÃO. Cartilha para conselheiros do Programa Nacional de Alimentação Escolar (PNAE). Brasília: Tribunal de Contas da União, 2017.

TRIBUNAL DE CONTAS DA UNIÃO. Orientações para conselhos da área de assistência social. Brasília: Tribunal de Contas da União, 2009.

TRIBUNAL DE CONTAS DO DISTRITO FEDERAL. Cartilha de orientação para conselheiros de saúde do DF. Brasília: Tribunal de Contas do Distrito Federal, 2018.

VAZ, Alexander Cambraia; PIRES, Roberto Rocha. "Comparações entre municípios: Avaliação dos efeitos da participação por meio de pares contrafactuais". In. PIRES, Roberto Rocha (org). Efetividade das instituições participativas no Brasil: Estratégias de avaliação. Brasília: Ipea, 2011, pp. 247-262.

NILO LIMA DE AZEVEDO (azevedo.nilo@uol.com.br) é professor da Universidade Estadual do Norte Fluminense Darcy Ribeiro (Uenf, Campos dos Goytacazes, Brasil). Possui doutorado pelo Programa de Pós-Graduação em Sociologia Política (PPGSP) da Uenf, mestrado pelo Programa de Pós-Graduação em Ciências Sociais (PPGCSO) da Universidade Federal de Juiz de Fora (UFJF, Brasil) e graduação em direito pela Universidade Candido Mendes (Ucam, Rio de Janeiro, Brasil).

https://orcid.org/0000-0003-3059-2441

$\begin{array}{lll}\text { MAURO MACEDO CAMPOS } & \end{array}$ (mauromcampos@yahoo.com.br) é professor associado da Uenf. Tem doutorado pelo Programa de Pós-Graduação em Ciência Política (PPGCP) da Universidade Federal de Minas Gerais (UFMG, Belo Horizonte, Brasil), mestrado pelo Programa de PósGraduação em Ciências Sociais (PPGCS) da Pontifícia Universidade Católica de Minas Gerais (PUC Minas, Belo Horizonte, Brasil) e graduação em ciências econômicas pelo Centro Universitário Newton Paiva (Newton Paiva, Belo Horizonte, Brasil).

https://orcid.org/0000-0001-9472-5165

RODRIGO ANIDO LIRA (rodrigoanidolira@gmail.com) é professor da Ucam. Tem doutorado pelo PPGSP da Uenf, mestrado pelo Programa de PósGraduação em Cognição e Linguagem (PPGCL) da Uenf e graduação em administração de empresas pela Universidade Federal Fluminense (UFF, Niterói, Brasil).

https://orcid.org/0000-0001-6217-9622 